from the Japanese Journal of Anaesthesiology. Such a preponderance casts doubt on the editor's claim to a wide range of coverage. A partial explanation may be that the papers selected are largely from the fields of academic anaesthesiology; very little clinical work is presented.

Of the 12 papers not from the dominant journal, six are from publications not on the list of journals surveyed, and indeed I could not trace five of the listed journals in any reference source available to me. It would be of interest to see a list of all the Japanese anaesthetic journals; the existence of, for example, The Hiroshima Journal of Anaesthesia, now apparently in its twenty-third year, is surely unknown to most anaesthetists outside Japan.

Two final suggestions. The browser through journals in the library would be helped if the titles of papers summarized, which are printed on the back cover of the journal, were classified by subject and placed under appropriate headings such as "Respiratory", "Endocrine" and so on. Also, knowledge of the Japanese literature would be helped by provision of a list of the contents of as many as possible of the appropriate Japanese journals, together with their addresses.

D.C. White is a consultant anaesthetist at Northwick Park Hospital, and an honorary member of scientific staff at the Medical Research Council Clinical Research Centre, Watford Road, Harrow, Middlesex HAI 3UJ, UK.

\section{Rhythm and reason}

\author{
Steven H. Strogatz
}

Journal of Biological Rhythms. Editor Benjamin Rusak. Guilford Press, 72 Spring Street, New York, NY 10012. $4 / y r$. US $\$ 75$ (institutional), $\$ 50$ (individual); elsewhere $\$ 90$ (institutional), $\$ 65$ (individual).

THE study of cycles has always attracted more than its share of crackpots. We are told that mysterious forces wax and wane, causing stock prices to rise and hemlines to fall. Another such lunacy maintains that three separate monthly 'biorhythms' govern our mental, physical and emotional well-being.

Small wonder that the study of biological rhythms has sometimes been regarded as a fringe subject. However, over the past three decades, this young field has become respectable. Daily ("circadian') rhythms have been documented in plants and animals, from unicells to human beings, and their endogenous generation by neural and cellular oscillators is now indisputable. There have been exciting advances in understanding the molecular genetics of clocks in Drosophila and in Neurospora. The
The unwilling host

\section{Robert J.M. Wilson}

Parasitology Today. Editor C.J. Schofield. Elsevier, Cambridge, UK. 12/yr. UK Dfl.500 (institutional), £30 (individual); North America Dfl.500 (institutional), \$53 (individual).

Parasitological journals tend to be dull: they take a scholarly approach and have conservative formats. Parasitology Today can be welcomed, therefore, as a ray of light cast on this otherwise sombre scene. Resonance from such photoexcitation could reach far, because today's parasitology is by no means dull.

Recent issues of Parasitology Today have dealt with neurotransmitters, hormones and population genetics, as well as offering reviews on standard themes such as immunology, vaccines, and the biology of particular parasitic organisms and their vectors. Like their subjects of study, parasitological disciplines tend to feed off the parent body of mainstream science. Hence the various categories of articles in the "Review", "Focus" and "Hitech" sections are very much descriptions of applications to parasitology. Nevertheless, there has been a renaissance of interest in, for instance, diagnostic techniques (previously one of the most boring, if important, aspects of parasitology) because of the application of biotechnology to this branch of the medical and veterinary side of the subject.

With its news, book review, letter and diary sections, Parasitology Today can provide an important forum where diverse facets of parasitology meet; as a meeting place it should suit the many newcomers

responses of the human circadian system to bright light and phase-shifting drugs are just beginning to be worked out, offering hope for jet-lagged travellers, insomniacs and night-shift workers.

As the increasingly diverse methods of modern biology are being used to investigate such questions, it has become more and more difficult to find a common home for research on biological rhythms. Now, Journal of Biological Rhythms provides an excellent forum for those concerned with the temporal organization of living things.

Each issue contains about six full-length reports of original research. The editors also welcome opinion papers and reviews of timely issues, though none appeared in the first volume. Announcements of meetings and prizes occasionally appear. Papers are published within six to eight months, and are printed in an uncrowded format with large, sharply reproduced figures. Most editors and contributors are from North America. to the field (students get a reduced subscription rate). With little injury or pain (except those inflicted on the sensibilities by a plethora of gruesome "medical plates'), molecular biologists can muse on alternative technologies or the chemotherapeutic control of diseases which they will probably never see except in their mind's eye.

Equally, the uninformed parasitologist can grapple with the complexities of branching structures in important glycoprotein molecules, confident that years of work have been condensed to a paragraph and that there is, besides, a cartoon which gets the point over in body language. At a more aesthetic level, I noted an arrestingly successful portrayal of falciparum malaria - from falx, falcis, a scythe shown as a skeletal figure reaping its harvest of Africa's children.

To introduce a carping note, it might be said that the punchy illustrative format of Parasitology Today verges on being overdone. Oversimplification and lack of substance are two obvious dangers which journals dealing in trends must guard against. If advice can be offered, it is that the core of serious, high-quality contributions should be maintained and if possible expanded. A difference both in the general level of content and restraint with illustrations is noticeable if one turns to Immunology Today for comparison.

The often extensive list of references allowed to reviewers, and the wide range of topics at their disposal, should enable the editors and contributors to Parasitology Today to fill the useful roles of disseminating both information and enlightenment whilst retaining a light touch.

Robert J.M Wilson is in the Parasitology Division. National Institute for Medical Research, Mill Hill, London NW7 IAA, UK.

The journal is off to a promising start. The leaders in the field are submitting some first-rate experimental research in genetics, cell biology, physiology and neuroscience. About three-quarters of the papers concern circadian rhythms, and the rest deal with photoperiodism and yearly rhythms. Topics that are currently underrepresented include modelling and statistical studies, as well as medical and pharmacological aspects of biological rhythms. These are addressed more often in Chronobiology International (reviewed in Nature 323, 363; 1986) and Chronobiologia, although the quality of papers in the latter journals is more uneven than those in Journal of Biological Rhythms.

Journal of Biological Rhythms has already published several fine articles. At this rate, it may well become the leading journal in the field.

Steven H. Strogatz is a Lecturer in the Divison of Applied Sciences, Harvard University, Cambridge, Massachussetts 02138, USA. 